\title{
Protective Effect of Quercetin Against Renal Toxicity Induced by Cadmium in Rats
}

\author{
Tevfik Aktoz ${ }^{1}$ Mehmet Kanter², Yeşim Hülya Uz², Cevat Aktaş ${ }^{3}$ Mustafa Erboğa², İrfan Hüseyin Atakan ${ }^{1}$ \\ ${ }^{1}$ Department of Urology, Faculty of Medicine, Trakya University, Edirne, Turkey \\ ${ }^{2}$ Department of Histology and Embryology, Faculty of Medicine, Trakya University, Edirne, Turkey \\ ${ }^{3}$ Department of Histology and Embryology, Faculty of Medicine, Namık Kemal University, Tekirdağ, Turkey
}

\begin{abstract}
Objective: The aim of the present study was to examine the protective effect of quercetine (QE) against cadmium (Cd)-induced renal toxicity.

Material and Methods: A total of 24 male Wistar albino rats were divided into three groups: control, Cd-treated and Cd-treated with QE; each group containing 8 animals. The $\mathrm{Cd}$-treated group was injected subcutaneously with $\mathrm{CdCl} 2$ dissolved in saline in the dose of $2 \mathrm{ml} / \mathrm{kg} / \mathrm{day}$ for 30 days, resulting in a dosage of $1 \mathrm{mg} / \mathrm{kg} \mathrm{Cd}$. The rats in the QE treated groups were given $\mathrm{QE}$ (15 mg/kg body weight) once a day intraperitoneally starting 2 days prior to $\mathrm{Cd}$ injection during the study period.
\end{abstract}

Results: The renal histology in Cd-treated rats showed mesangial expansion, thickening of capsular basement membranes, glomerular basement membranes and tubular basement membranes, characterized by an increase in periodic acid Schiff (PAS)-positive areas as compared with control animals. With the QE treatment, despite the presence of only a few swollen glomeruli, we noticed a marked protection of renal structure when compared with the Cd-treated rats. Furthermore, QE pretreatment resulted in increased proliferating cell nuclear antigen (PCNA) immunoreactivity and decreased the activity of Terminal Transferase dUTP Nick End Labeling (TUNEL).

Conclusion: These findings suggest that QE may attenuate $\mathrm{Cd}$-induced renal toxicity.

Key Words: Cadmium, immunohistochemistry, quercetin, renal toxicity, TUNEL

Received: 13.01.2011

Accepted: 14.04 .2011

\section{Introduction}

Cadmium (Cd) is a heavy metal present in air, water, soils, and sediments $(1,2)$. Cd accumulates largely in the liver and kidney and produces pulmonary, liver, and renal tubular diseases. Chronic intake of $\mathrm{Cd}$ in food or in air produces organ dysfunction as a result of cell death (3). Cd is widely used in pigments, plastic stabilizers, electroplating, alloys, nickel-Cd batteries, and welding in industry and is also present in tobacco $(4,5)$. Natural sources of $\mathrm{Cd}$ are spread into the atmosphere by volcanic activity, forest fires, and wind-blown transport of soil particles. Other sources are phosphate fertilizers, which may contain high concentrations of $\mathrm{Cd}$, depending on the origin of the rock, and the application of contaminated sewage sludge as a soil additive (1). It has been demonstrated that the kidney is one of the most critically affected organs follorwing long-term environmental and occupational exposure to $\mathrm{Cd}(1,6)$. Cd-induced nephropathy is characterized functionally by various signs of tubular dysfunction, such as low molecular weight proteinuria, glucosuria, and aminoaciduria, and pathologically by chronic interstitial nephritis (6).

Flavonoids are a group of naturally occurring compounds widely distributed as secondary metabolites in the plant kingdom. They are recognized as having interesting clinical properties, such as anti-inflammatory, antiallergic, antiviral, antibacterial, and antitumoral activities [7]. One of these flavonoids, quercetin (QE) (3, 5, 7, 3', 4'-pentahydroxyflavone), prevents oxidant injury and cell death by several mechanisms, such as scavenging oxygen radicals, protecting against lipid peroxidation and chelating metal ions (8-10).

The aim of the present study was to examine the protective effect of $\mathrm{QE}$ against $\mathrm{Cd}$-induced renal toxicity.

\section{Material and Methods}

\section{Animals}

Twenty four healthy male Wistar albino rats, (weighing 200-250 $\mathrm{g}$ and averaging 16 weeks old) housed at the Trakya University Animal Care and Research Unit, were used for this study. Food and tap water were available ad libitum. In the windowless animal quarter automatic temperature $\left(21 \pm 1^{\circ} \mathrm{C}\right)$ and lighting controls (12 h light/12 h dark cycle) were maintained. Humidity ranged from $55 \%$ to $60 \%$. All animals received humane care according to the criteria outlined in the "Guide for the Care and Use of Laboratory Animals" prepared by the National Academy of Sciences and published by 
the National Institutes of Health. In addition, the experimental protocol was approved by the Ethical Committee of Trakya University Medical Faculty (approved date and number: 05/01/2011 and 2011.01.010). QE was obtained from Sigma Chemical (St Louis, MO, USA) and dissolved in $0.5 \mathrm{ml}$ of $60 \%$ ethanol just before intraperitoneal (i.p.) injection (15 mg/kg). The control group was injected with the same volume of saline as the $\mathrm{Cd}$ treated groups received.

\section{Experimental groups}

A total of 24 male Wistar albino rats were divided into three groups: control, $\mathrm{Cd}$-treated and $\mathrm{Cd}$-treated with $\mathrm{QE}$; each group containing 8 animals. Control animals received daily injections of the saline vehicle alone. The $\mathrm{Cd}$-treated group were injected subcutaneously with $\mathrm{CdCl}_{2}$ dissolved in saline at a dose of $2 \mathrm{ml} / \mathrm{kg} /$ day for 30 days, resulting in a dosage of $1 \mathrm{mg} / \mathrm{kg} \mathrm{Cd}$ (11). The rats in QE treated groups were given $\mathrm{QE}$ (15 mg/kg body weight) once a day intraperitoneally starting 2 days prior to the $\mathrm{Cd}$ injection during the study period. At the end of the study, all animals were anesthetized with an i.p. injection of sodium thiopenthal $(100 \mathrm{mg} / \mathrm{kg}$, Sigma, St. Louis, MO, USA). After twenty minutes, the anesthetized rats were sacrificed and renal tissues were removed for histopathological investigation.

\section{Histopathologic evaluation}

The renal tissues were individually immersed in Bouin's fixative, dehydrated in alcohol and embedded in paraffin. Sections of $5 \mu \mathrm{m}$ were obtained, deparaffinized and stained with hematoxylin and eosin (H\&E) and periodic acid Schiff (PAS). The renal tissue was examined and evaluated in random order under blindfold conditions with standard light microscopy.

The thickening of the renal basement membrane was scored in a semiquantitative manner in order to determine the differences between the control group and the experimental groups. The thickening of the renal basement membrane was recorded as normal $(+)$, thick $(++)$, very thick $(+++)$ and extremely thick $(++++)$. These analyses were performed in two sections from each animal at $\times 400$ magnification in at least ten different regions for each section.

\section{Immunohistochemistry}

The harvested renal tissues were fixed in Bouin's, embedded in paraffin and sectioned at $5 \mu \mathrm{m}$ thickness. Immunohistochemical reactions were performed according to the $A B C$ technique described by $\mathrm{Hsu}$ et al. (12). The procedure involved the following steps: (1) endogenous peroxidase activity was inhibited by $3 \% \mathrm{H}_{2} \mathrm{O}_{2}$ in distilled water for $30 \mathrm{~min}$; (2) the sections were washed in distilled water for $10 \mathrm{~min}$; (3) non-specific binding of antibodies was blocked by incubation with normal goat serum (DAKOX0907, Carpinteria, CA) with phosphate-buffered saline (PBS), diluted 1:4 (4). The sections were incubated with specific mouse monoclonal anti-PCNA antibody (Cat. \# MS-106-B, Thermo LabVision, USA), diluted 1:50 for $1 \mathrm{~h}$ at room temperature; (5) then washed in PBS $3 \times 3 \mathrm{~min}(6)$. The sections were incubated with biotinylated anti-mouse IgG (DAKO LSAB $2 \mathrm{Kit}$ ); (7) andwere washed in PBS $3 \times 3 \mathrm{~min}$; (8) then incubated with $A B C$ complex (DAKO LSAB
2 Kit) (9). The sections were washed in PBS $3 \times 3$ min; (10) peroxidase was detected with an aminoethylcarbazole substrate kit (AEC kit; Zymed Laboratories); (11) the sections were then washed in tap water for 10 min and then dehydrated; (12) the nuclei were stained with hematoxylin; and (13) the sections were mounted in DAKO paramount. All dilutions and thorough washes between steps were performed using PBS unless otherwise specified. All steps were carried out at room temperature. As a negative control, the primary antibody was replaced with $\mathrm{PBS}$.

\section{TUNEL assay}

The TUNEL method, which detects fragmentation of DNA in the nucleus during apoptotic cell death in situ, was employed using an apoptosis detection kit (TdT-Fragel ${ }^{\mathrm{TM}}$ DNA Fragmentation Detection Kit, Cat. No. QIA33, Calbiochem, USA). All reagents listed below are from the kit and were prepared following the manufacturer's instructions. 5- $\mu$ m-thick renal sections were deparaffinized in xylene and rehydrated through a graded ethanol series as described previously. They were then incubated with $20 \mathrm{mg} / \mathrm{ml}$ proteinase $\mathrm{K}$ for 20 minutes and rinsed in TBS. Endogenous peroxidase activity was inhibited by incubation with $3 \%$ hydrogen peroxide. Sections were then incubated with equilibration buffer for 10-30 minutes and then TdT-enzyme, in a humidified atmosphere at $37^{\circ} \mathrm{C}$, for 90 minutes. They were subsequently put into prewarmed working strength stop/wash buffer at room temperature for 10 minutes and incubated with blocking buffer for 30 minutes. Each step was separated by thorough washes in TBS. Labelling was shown using $D A B$, counter staining was performed using methyl green, and sections were dehydrated, cleared and mounted.

The number of PCNA and TUNEL positive cells in each specimen was also scored. Ten randomly selected areas were scored for each specimen in every experiment as follows: $0=$ no positive response; $1=$ less than $10 \%$ of cells; $2=11-20 \%$ of cells; $3=21-40 \%$ of cells; $4=$ more than $40 \%$ of cells.

\section{Statistical analysis}

All statistical analyses were carried out using SPSS statistical software (SPSS for windows, version 11.0). All data were presented in mean ( \pm ) standard deviations (S.D.). Differences in measured parameters among the three groups were analyzed with a nonparametric test (Kruskal-Wallis). Dual comparisons between groups exhibiting significant values were evaluated with a Mann-Whitney U-test. These differences were considered significant when probability was less than 0.05 .

\section{Results}

\section{Histopathological findings}

Normal structure of the renal cortical tissue was observed in control rats (Figure 1a). The animals exposed to $\mathrm{Cd}$ showed severe changes in the renal tubules and glomeruli. Hypertrophy and degeneration of renal tubules epithelia with infiltration of mononuclear cells, increased amounts of mesangial matrix and dilatation of glomeruli were evident in all animals treated with $\mathrm{Cd}$ (Figure 1b). With the QE treatment, despite 

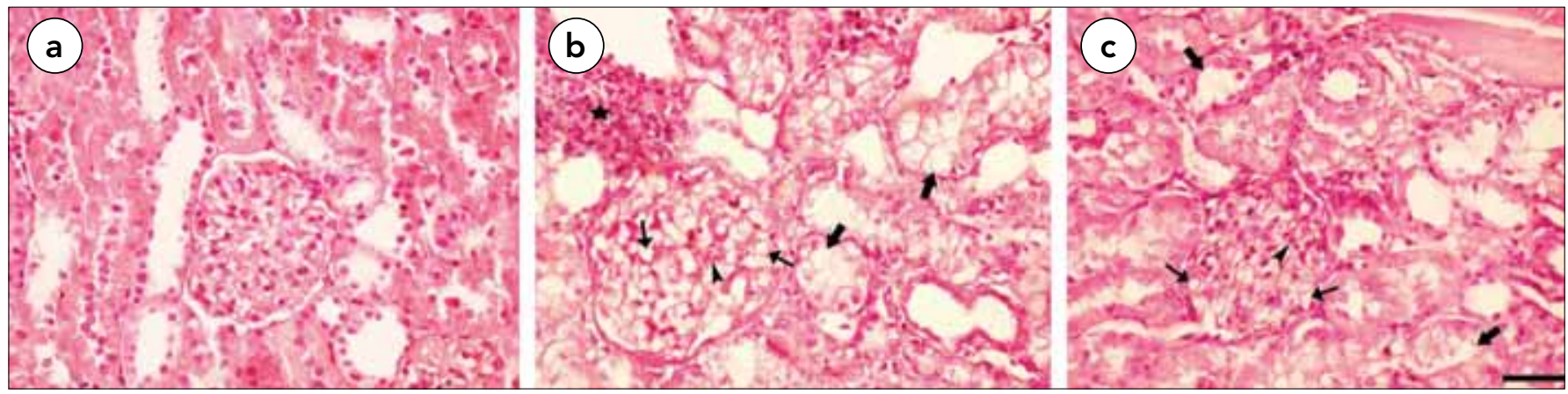

Figure 1. Light microscopy of renal cortical tissues in different groups. (a) In controls, normal renal cortical tissue architecture was seen; (b) In Cd-treated group, increased amounts of mesangial matrix, dilatation of glomeruli, tubuli and mononuclear cell infiltration; (c) Treatment of QE reduced the amounts of mesangial matrix, dilatation of glomeruli, tubuli and mononuclear cell infiltration (arrow head: mesangial matrix, thin arrows: glomerular dilatation, thick arrows: tubular dilatation, asterisk: mononuclear cell infiltration), (H\&E, scale bar, $50 \mu \mathrm{m}$ )

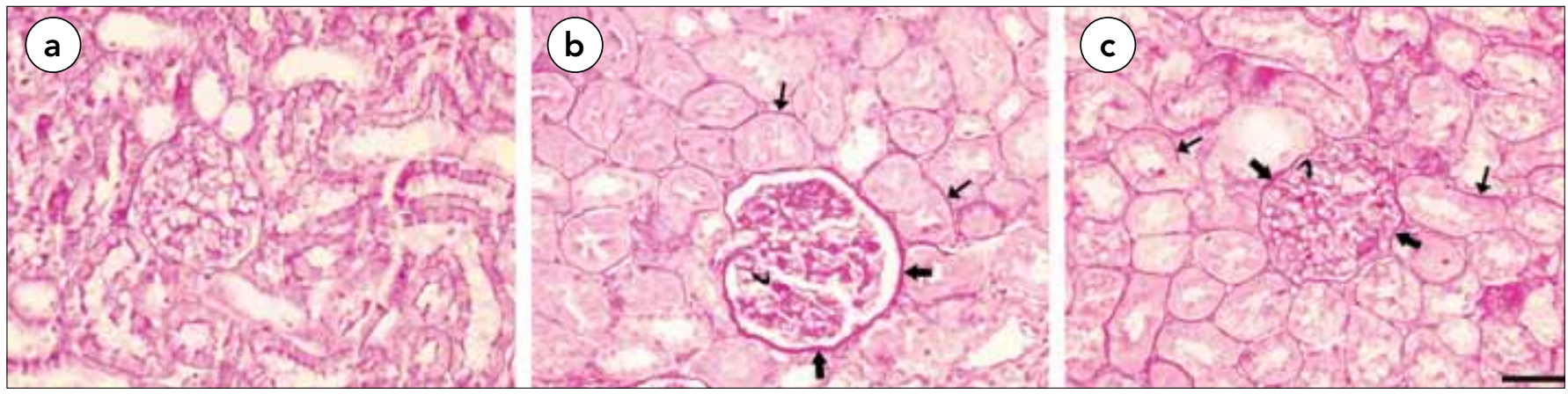

Figure 2. Light microscopy of renal cortical tissues in different groups. (a) In controls, normal renal cortical architecture was seen; $(b, c)$ Decreased the thickened CBMs, GBMs and TBMs in Cd-treated with QE rats as compared with Cd-treated rats. (oblique arrows: CBMs PAS positive area, thick arrows: TBMs PAS positive area, thin arrows: GBMs PAS positive area), (PAS, scale bar, $50 \mu \mathrm{m}$ )

the presence of only a few swollen glomeruli and tubuli, we noticed a marked protection in renal structure when compared with the Cd-treated rats (Figure 1c). Moreover, the renal histology in $\mathrm{Cd}$-treated rats showed an enlargement of the glomeruli, mesangial expansion, thickening of capsular basement membranes (CBMs), glomerular basement membranes (GBMs), and tubular basement membranes (TBMs), characterized by an increase in PAS-positive area as compared with control animals (Figure 2a, b). Treatment of QE reduced the glomerular size, thickening of CBMs, GBMs and TBMs as compared with the $\mathrm{Cd}$-treated group (Figure 2c; Table 1).

\section{Immunohistochemical findings}

PCNA-positive cells were strongly detected in the renal cortical tissues of the control rats (Figure 3a). However, the signal density of positive cells was significantly higher in the $\mathrm{Cd}$-treated group (Figure $3 \mathrm{~b}$ ). Treatment of QE markedly increased the reactivity of PCNA in the renal cortical tissues (Figure 3c; Table 2).

\section{TUNEL findings}

The number of TUNEL-positive cells in the control group was negligible (Figure 4a). When kidney sections were TUNEL stained, there was a clear increase in the number of positive cells in the $\mathrm{Cd}$-treated rats in the renal cortical tissues (Figure
Table 1. Semiquantitative comparison of the thickening of renal basement membrane in control, $\mathrm{Cd}$-treated and $\mathrm{Cd}$ treated with QE groups

\begin{tabular}{|c|c|c|c|}
\hline & Control & Cd-treated & $\begin{array}{l}\text { Cd-treated } \\
\text { with QE }\end{array}$ \\
\hline $\begin{array}{l}\text { Basement } \\
\text { membrane thickening }\end{array}$ & + & ++++ & ++ \\
\hline \multicolumn{4}{|c|}{$\begin{array}{l}\text { The thickening of the renal basement membrane was recorded as normal } \\
(+) \text {, thick }(++) \text {, very thick }(+++) \text { and extremely thick }(++++)(\mathrm{n}: 8 \text { for each } \\
\text { group) }\end{array}$} \\
\hline
\end{tabular}

4b). Treatment of QE markedly reduced the reactivity and the number of TUNEL positive cells (Figure 4c, Table 2).

\section{Discussion}

$\mathrm{Cd}$ is a toxic, industrial and environmental metal $(2,5$, $13,14)$. The major enviromental source of $\mathrm{Cd}$ for humans and animals is food and drinking water (15). With increasing production and utilization of $\mathrm{Cd}$, not only industrial workers, but also the general population are also exposed to the toxic effects of $\mathrm{Cd}$. It has been found that $\mathrm{Cd}$ produces various pathological conditions, including hepatic and renal dysfunctions, testicular damage, and respiratory and nervous system disorders (13, 14, 
In a recent study (23), PCNA-immunoreactive cells were preferentially detected in the degenerating proximal tubular lesions observed histopathologically in animals treated with $\mathrm{CdCl}_{2}$ at 200 and $600 \mathrm{ppm}$. Significantly, increases in PCNA were also found in these high-dose $\mathrm{Cd}$-treated groups. In the experiment, the severity of proximal tubular degeneration and the mitotic figures in such degenerating tubules correlated well with both renal $\mathrm{Cd}$-concentrations and PCNA in the proximal tubular epithelium. To date, no PCNA expression on $\mathrm{Cd}$-induced renal toxicity in rats by $\mathrm{QE}$ treatment have been reported. In the present study, the signal density of positive cells was significantly higher in Cd-treated group. Treatment with QE markedly increased the reactivity of PCNA in the renal cortical tissues.

Both necrotic and apoptotic mechanisms have been implicated in the pathways leading to the death of proximal tubule epithelial cells during exposure to $\mathrm{Cd}$. High levels of $\mathrm{Cd}$ are clearly capable of causing proximal tubule necrosis $(22,24)$. However, other studies indicate that the early stages of $\mathrm{Cd}$ nephrotoxicity primarily involve apoptosis of proximal tubule epithelial cells, with little evidence of necrosis $(25,26)$. Moreover, results of several recent studies suggest that the early stages of Cd-nephrotoxicity may involve changes in cell adhesion molecule function and cytoskeletal organization that occur before the onset of either necrotic or apoptotic death of proximal tubule epithelial cells $(27,28)$.

Recently, Iwai and Matsuno (29) have shown that chronic $\mathrm{Cd}$ exposure induces apoptosis and subsequent regeneration of the renal tubular epithelium in rats and beagle dogs, respectively. Apoptosis, a distinctive form of cell death, which occurrs in various tissues under certain physiological or pathological conditions (30), differs obviously from necrosis. Thus, since apoptosis may be one of the main features of $\mathrm{Cd}$ intoxication, it seems necessary to conduct more effective studies on the phenomenon in the tubular epithelium after exposure to higher doses of $\mathrm{Cd}$. In one study (26), the basement membrane was intact and no macrophages infiltration was found in tubular epithelium. Furthermore, since the regenerating tubular cells actively proliferated and replaced the epithelium, the dead cells seemed to be pushed out into the tubular lumen. The cell interfaces between the regenerating cells and the dead cells were simple without any cytoplasmic infoldings or junctional complexes. In vitro experimental studies using proximal tubular cells have shown that $\mathrm{Cd}$ damages $\mathrm{F}$-actin and disrupts intercellular junctions (31). These junctional changes might result in easy detachment of dead cells from the tubular lining.

In a more recent study, Aoyagi et al. (25) noted an increase in the number of TUNEL-labeled cells in the renal cortex of $\mathrm{Cd}$ treated rats after 4 and 5 weeks of exposure, but the level of apoptotic labeling was much less pronounced after 6 and 8 weeks of exposure. However, no quantitative data was included in their analysis. In our present study, the number of TUNEL positive cells was semi-quantitatively higher in the Cd-treated group than the control group. Treatment with QE markedly reduced the reactivity and the number of TUNEL positive cells. In conclusion, these findings suggest that QE may attenuate Cd-induced renal toxicity.

\section{Conflict of Interest}

No conflict of interest was declared by the authors.

\section{References}

1. Waisberg $M$, Joseph $P$, Hale B, Beyersmann D. Molecular and cellular mechanisms of cadmium carcinogenesis. Toxicology 2003;192:95-117. [CrossRef]

2. Koçak M, Akçil E. The effects of chronic cadmium toxicity on the hemostatic system. Pathophysiol Haemost Thromb 2006;35:411-6. [CrossRef]

3. Kim SC, Cho MK, Kim SG. Cadmium-induced nonapoptotic cell death mediated by oxidative stress under the condition of sulfhydryl deficiency. Toxicol Lett 2003;144:325-36. [CrossRef]

4. Ohta H, Yamauchi Y, Nakakita M, Tanaka H, Asami S, Seki Y, et al. Relationship between renal dysfunction and bone metabolism disorder in male rats after long-term oral quantitative cadmium administration. Industr Health 2000;38:339-55. [CrossRef]

5. Washington B, Williams S, Armstrong P, Mtshali C, Robinson JT, Myles EL. Cadmium toxicity on arteriols vascular smooth muscle cells of spontaneously hypertensive rats. Int J Environ Res Public Health 2006;3:232-8. [CrossRef]

6. Bernard A, Lauwerys R. Effects of cadmium exposure in humans. In Handbook of Experimental Pharmacology (E. C. Foulkes, Ed.), Springer-Verlag, Heidelberg 1986;135-77.

7. Middleton E Jr. Effect of plant flavonoids on immune and inflammatory cell function. Adv Exp Med Biol 1998;439:175-82. [CrossRef]

8. Inal ME, Akgun A, Kahraman A. Radioprotective effects of exogenous glutathione against whole-body gamma-ray irradiation: age- and gender-related changes in malondialdehyde levels, superoxide dismutase and catalase activities in rat liver. Methods Find Exp Clin Pharmacol 2002;24:209-12. [CrossRef]

9. Laughton MJ, Evans PJ, Moroney MA, Hoult JR, Halliwell B. Inhibition of mammalian 5-lipoxygenase and cyclo-oxygenase by flavonoids and phenolic dietary additives. Relationship to antioxidant activity and to iron ion-reducing ability. Biochem Pharmacol 1991;42:1673-81. [CrossRef]

10. Afanas'ev IB, Dorozhko I, Brodskii AV, Korstyuk VA, Potapovitch A. Chelating and free radical scavenging mechanisms of inhibitory action of rutin and quercetin in lipid peroxidation. Biochem Pharmacol 1989;38:1763-9. [CrossRef]

11. Scott R, Aughey E, Sinclair J. Histological and ultrastructural changes in rat kidney following cadmium injection. Urol Res 1977;5:15-20. [CrossRef]

12. Hsu SM, Raine L, Fanger H. Use of avidinbiotin-peroxidase complex $(A B C)$ in immunperoxidase techniques: a comparison between $A B C$ and unlabeled antibody (PAP) procedures. J Histochem Cytochem 1981;29:577-80. [CrossRef]

13. Yiin SJ, Chern CL, Sheu JY, Lin TH. Cadmium-induced lipid peroxidation in rat testes and protection by selenium. Biometals 1999;12:353-9. [CrossRef]

14. Yiin SJ, Chern CL, Sheu JY, Tseng WC, Lin TH. Cadmium-induced renal lipid peroxidation in rats and protection by selenium. J Toxicol Environ Health 1999;57:403-13. [CrossRef]

15. Ohta H, Cherian MG. Gastrointestinal absorption of cadmium and metallothionein. Toxicol Appl Pharmacol 1991;107:63-72. [CrossRef]

16. Nigam D, Shukla GS, Agarwal AK. Glutathione depletion and oxidative damage in mitochondria following exposure to cadmium in rat liver and kidney. Toxicol Lett 1999;106:151-7. [CrossRef]

17. Newairy AA, El-Sharaky AS, Badreldeen MM, Eweda SM, Sheweita SA. The hepatoprotective effects of selenium against cadmium toxicity in rats. Toxicology 2007;242:23-30. [CrossRef]

18. Asar M, Kayisli UA, Izgut-Uysal VN, Akkoyunlu G. Immunohistochemical and ultrastructural changes in the renal cortex of cadmium-treated rats. Biol Trace Elem Res 2004;97:249-63. [CrossRef] 
19. Takaki A, Jimi S, Segawa M, Hisano S, Takebayashi S, Iwasa$\mathrm{ki} \mathrm{H}$. Longterm cadmium exposure accelerates age-related mitochondrial changes in renal epithelial cells. Toxicology 2004;203:145-54. [CrossRef]

20. Griffin JL, Walker LA, Shore R, Nicholson JK. Metabolic profiling of chronic cadmium exposure in the rat. Chem Res Toxicol 2001;14:1428-34. [CrossRef]

21. Gatta A, Bazzerla G, Amodio P, Menon F, Angeli P, Schiaffino $E$, et al. Detection of the early steps of cadmium nephropathycomparison of light- and electron-microscopical patterns with the urinary enzymes excretion. An experimental study. Nephron 1989;51:20-4. [CrossRef]

22. Goyer RA, Miller CR, Zhu S, Victery W. Non-metallothioneinbound cadmium in the pathogenesis of cadmium nephrotoxicity in the rat. Toxicol Appl Pharmacol 1989;101:232-44. [CrossRef]

23. Shibutani M, Mitsumori K, Niho N, Satoh S, Hiratsuka H, Satoh M, et al. Assessment of renal toxicity by analysis of regeneration of tubular epithelium in rats given low-dose cadmium chloride or cadmiumpolluted rice for 22 months. Arch Toxicol 2000;74:571-7. [CrossRef]

24. Brzoska MM, Kaminski M, Supernak-Bobko D, Zwierz K, Moniuszko-Jakoniuk J. Changes in the structure and function of the kidney of rats chronically exposed to cadmium. I. Biochemical and histopathological studies. Arch Toxicol 2003;77:344-52.
25. Aoyagi T, Hayakawa K, Miyaji K, Ishikawa H, Hata M. Cadmium nephrotoxicity and evacuation from the body in a rat modeled subchronic intoxication. Int J Urol 2003;10:332-8. [CrossRef]

26. Tanimoto A, Hamada $T$, Koide $O$. Cell death and regeneration of renal proximal tubular cells in rats with subchronic cadmium intoxication. Toxicol Pathol 1993;21:341-52. [CrossRef]

27. Jacquillet G, Barbier O, Cougnon M, Tauc M, Namorado MC, Martin D, et al. Zinc protects renal function during cadmium intoxication in the rat. Am J Physiol Renal Physiol 2006;290:F127-37. [CrossRef]

28. Prozialeck WC, Vaidya VS, Liu J, Waalkes MP, Edwards JR, Lamar PC, et al. Kidney injury molecule-1 (Kim-1) as an early biomarker of cadmium nephrotoxicity. Kidney Int 2007;72:985-93. [CrossRef]

29. Iwai S, Matsuno K. An ultrastructual study on cadmium-induced damage of the renal proximal tubules of rats. J Med Soc Toho 1991;137:757-71.

30. Walker NI, Harmon BV, Gobé GC, Kerr JF. Patterns of cell death. Meth Archiev Exp Pathol 1988;13:18-54.

31. Prozialeck WC, Niewcnhuis RJ. Cadmium $(\mathrm{Cd} 2+)$ disrupts intercellularjunctions and actin filaments in LLC-PKI cells. Toxicol Appl Pliarmacol 1991;107:81-97. [CrossRef] 